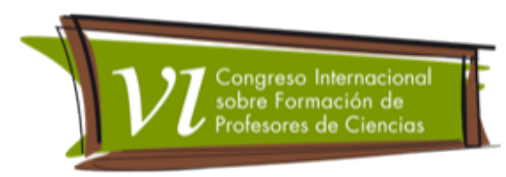

\title{
Perspectivas De Género En Profesores Reflexiones Desde La Imagen Científica Femenina
}

Arias Lancheros, Javier ${ }^{1}$ y Sanabria Rojas Quira ${ }^{2}$

Categoría 2. Trabajo de investigación

\section{Resumen}

Los profes@res de manera general se visualizan como uno de los agentes de cambio de la sociedad, y en su hacer profesional muchas veces la desigualdad de género se presenta sin que se percaten de este, a pesar de que se promulgue y se diseñen contextos en donde predomine la igualdad de condiciones. Por lo general la no identificación del fenómeno social se atribuye a que están insertos en ese modelo de lo femenino y de lo masculino que se ha construido en la sociedad de la que hacen parte. Un ejemplo de lo dicho está en los libros de literatura que se estudian en el aula de clase los cuales predominan unas personas sobre otras, en estos difícilmente se trabaja los contextos científicos donde se desarrollaron los hechos, validando y fortaleciendo el imaginario de una ciencia a-política, y a-histórica (Rossetti, 1994).

Con la siguiente propuesta de trabajo se pretende identificar las perspectivas de género que los profesores en formación inicial (P.F.I) de Licenciatura en Química de la Universidad Pedagógica Nacional fueron adquiriendo y que indirectamente son asociadas a la formación científica que se han construido a través de diferentes experiencias escolares, y es en esta dirección que hay que pensar el cómo influye las diferentes perspectivas de genero a la hora de edificar una identidad profesional $Y$ de una manera $U$ otra llegan a ser transmitidas por medio de la enseñanza.

Buscando fortalecer las diferentes perspectivas de género en P.F.I se propone la utilización de Las genealogías como recursos retrospectivos e ilustrados que plantean estrategias para la Re-significación del valor cultural del saber cómo producto humano centrado en los sujetos y no en el género, Que podrán favorecer y fortalecer la identidad profesional y un sentido de lo propio que

\footnotetext{
${ }^{1}$ Universidad pedagógica nacional, holatodoscomo@hotmail.com

${ }^{2}$ Universidad pedagógica nacional, qsanabria@gmail.com
} 
Revista Tecné, Episteme y Didaxis: TED. Año 2014, Número Extraordinario. ISSN Impreso: 0121-3814, ISSN web: 2323-0126

Memorias, Sexto Congreso Internacional sobre Formación de Profesores de Ciencias. 08 al 10 de octubre de 2014, Bogotá

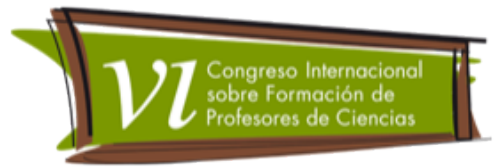

pone en primer plano una de las responsabilidades sociales de la educación la cual es formar para la participación, la identidad, desarrollando la capacidad crítica, reflexiva y analítica que fortalezca el avance científico según Ley general de educación 115 (1994).

\section{Palabras clave}

Genero, educación, profesores en formación, genealogías.

\section{Introducción}

Con el siguiente trabajo de investigación que tiene lugar en la Universidad Pedagógica Nacional, principalmente en el Departamento de Química, tiene como fin identificar las perspectivas de género, en profesores de formación inicial (PFI) de la Licenciatura en Química asociadas a la formación científica proveniente de experiencias escolares anteriores y la relación con la identidad profesional que estos tienen y escogen, buscando contribuir con la realización de algunas genealogías de mujeres científicas destacadas en Química.

Las ciencias naturales como todas las ciencias existentes, están articuladas por una historia; historia que muchas veces es sesgada, puesto que se ha reducido a los hechos que acontecieron en un primer momento, quitando la posibilidad de darle un contexto social, político, económico que en palabras de Lakatos (1978) puede considerarse un escenario internalista de las ciencias.

Dentro de la búsqueda de antecedentes, se tuvieron en cuenta diferentes artículos de revistas y trabajos de grado, nacionales e internacionales, que sirvieron de soporte para la actual propuesta.

Daza y Pérez (2008) menciona como objetivo principal revisar el papel que tienen los indicadores sociales en relación con el género en el campo de la ciencia y la tecnología. "contado mujeres, Una reflexión sobre los indicadores de género y ciencia en Colombia" como lo indica el título de su trabajo les permitió analizar qué se han hecho en Latinoamérica por parte de la UNESCO, OEA, OCDE. Se alerta sobre el papel de los indicadores, puesto que siendo sólo un criterio numérico no es directo el valor de objetividad de los resultados, sobre todo porque siendo una herramienta muy utilizada en ciencia de corte androcéntrista, los avances metodológicos en investigación contemporánea admiten que no se considera un elemento contundente que supere a las reflexiones narrativas que de ellos se pueda elaborar. De igual manera se 
Revista Tecné, Episteme y Didaxis: TED. Año 2014, Número Extraordinario. ISSN Impreso: 0121-3814, ISSN web: 2323-0126

Memorias, Sexto Congreso Internacional sobre Formación de Profesores de Ciencias. 08 al 10 de octubre de 2014, Bogotá

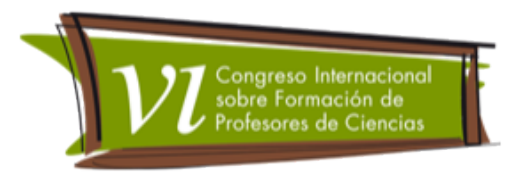

considera valiosos de rescate por ser resultados para fundamentar políticas públicas que atiendan la brecha existente de géneros en la ciencia.

Frente a la manera como se han hecho estos estudios los cuales deben girar en torno a las siguientes preguntas; ¿̇qué intereses de investigación tienen? ; ¿Qué tipo de producciones intelectuales han realizado?; ¿cuáles son sus niveles de colaboración?; ¿cómo dialoga este tipo de producción e intereses con lo que hacen sus compañeros investigadores? (Daza y Pérez ,2008).

Que condujo a que nos preguntáramos sobre el tipo de imaginarios que sobre la producción y aporte científico de mujeres visibiliza, reconoce y divulga un licenciado del área de las ciencias naturales.

En este ejercicio se encontró resultados comparativos sobre las mujeres doctoras en Química egresadas de establecimientos universitarios colombianos, trabajo de grado terminado en el año 2012, como objetivo principal se propuso evidenciar el número de mujeres en doctorados en la actualidad, cuántas son visualizadas, cuál es su volumen de publicaciones en revistas indexadas (Díaz y Susa ,2012), en el que afirman que la participación de las mujeres científicas en Colombia es muy alta, pero su visibilización no es igual a su participación, pareciera como si estuviese mediando una ciencia hegemónica ligada a la relación de género .

La gráfica 1. llustra desde los indicadores una relación entre género masculino y femenino el acceso y beneficio a becas para estudios posgraduales a nivel de maestría.

Gráfica 1: Becas, crédito y becas-crédito para maestrías según el sexo del beneficiario. Donde se evidencia la participación de las mujeres en estudios de maestría, pero cuando se compara con los de los hombres hay una brecha por género, solo hasta el año 2011 que al parecer la brecha se reduce. Imagen tomada de Observatorio Colombiano De Ciencia Y Tecnología, OC y T(2012). 
Revista Tecné, Episteme y Didaxis: TED. Año 2014, Número Extraordinario. ISSN Impreso: 0121-3814, ISSN web: 2323-0126

Memorias, Sexto Congreso Internacional sobre Formación de Profesores de Ciencias. 08 al 10 de octubre de 2014, Bogotá
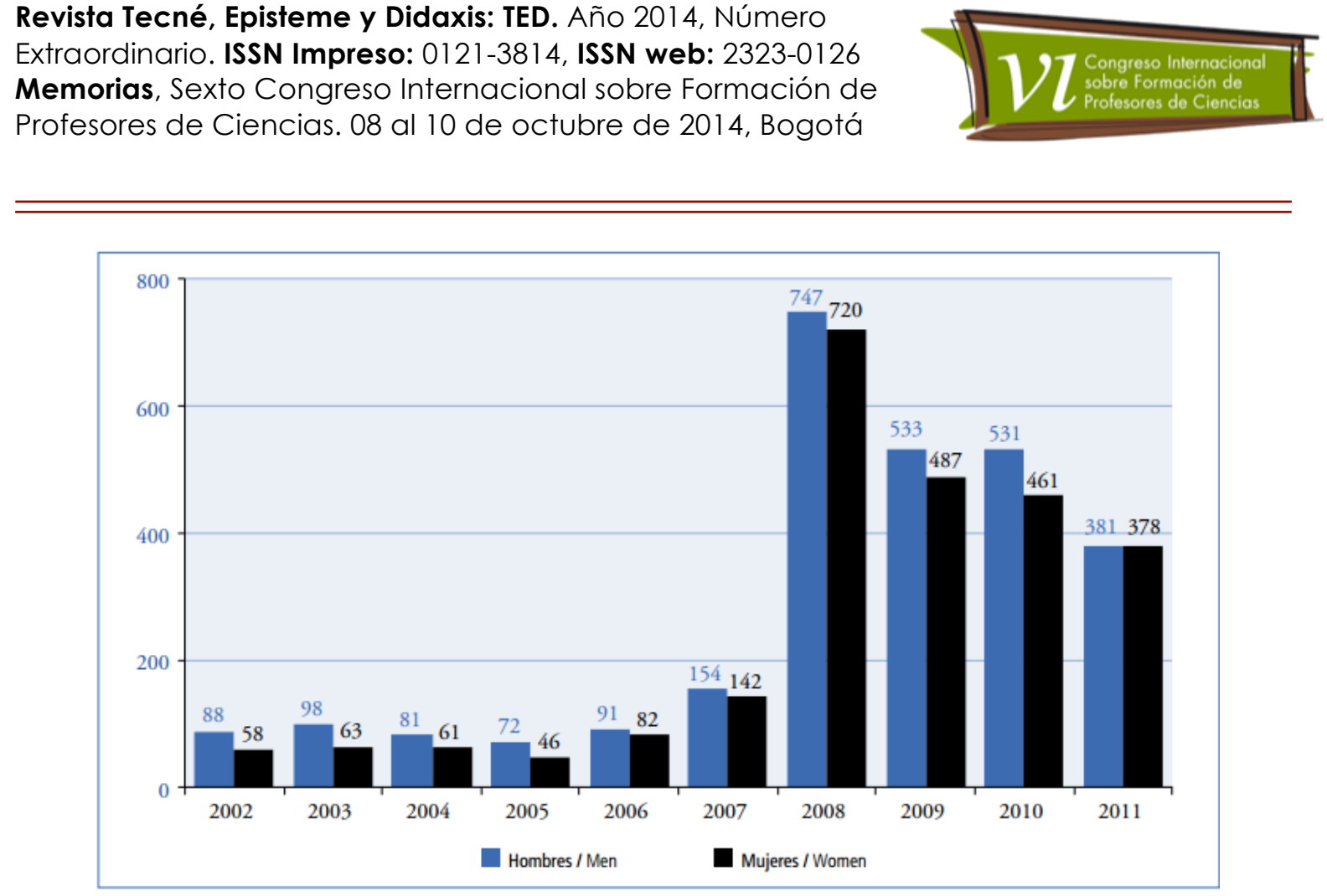

La imagen refleja el aumento exponencial de participación en general siendo muy próximas las cifras de beneficiados.

Sin embargo, tal situación no se mantiene a la hora de hacer los comparativos con acceso y beneficio de becas de nivel de doctorado, la gráfica 2 permite visualizar lo dicho.

Gráfica 2: becas, crédito y becas-crédito para doctorados según el sexo del beneficiario. Dicha gráfica permite mostrar la brecha que a comparación con la gráfica 1 de estudios de maestría se profundiza aún más según el sexo, a la hora de realizar estudios de doctorado, puede decir con estos datos estadísticos que cada vez que se aumenta en estudios la mujer es superada en el doble de oportunidades por sus homólogos. 
Revista Tecné, Episteme y Didaxis: TED. Año 2014, Número Extraordinario. ISSN Impreso: 0121-3814, ISSN web: 2323-0126

Memorias, Sexto Congreso Internacional sobre Formación de Profesores de Ciencias. 08 al 10 de octubre de 2014, Bogotá
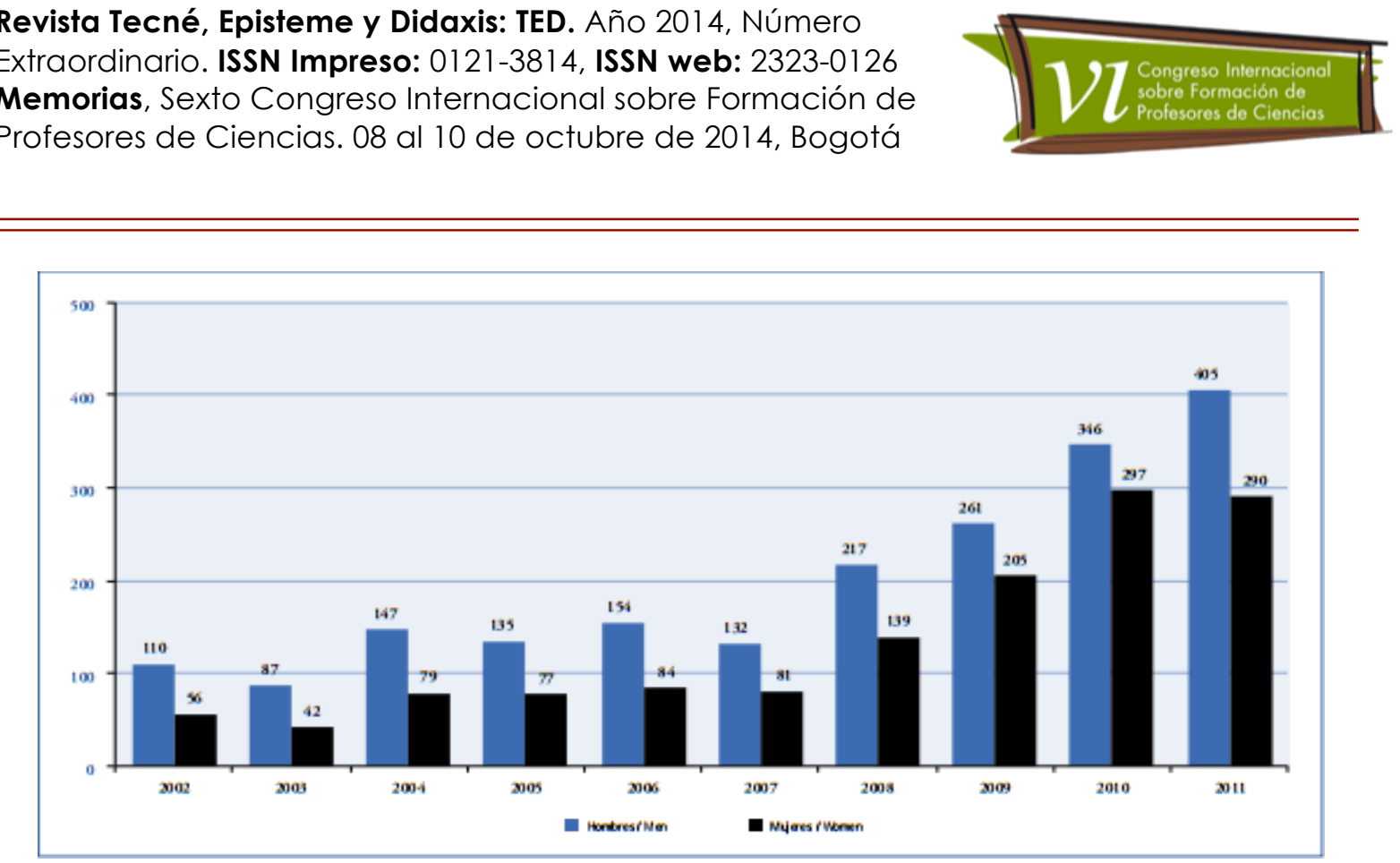

Imagen tomada de Observatorio Colombiano De Ciencia Y Tecnología, OC y T (2012).

Como se observa los 10 años comparados muestran un aumento de ingreso a estudios doctorales de ambos géneros, sin embargo, la diferencia entre beneficiarios hombres y mujeres es evidente, más los estudios no ilustran las posibles razones de dichos resultados.

Otros estudios adelantados indican que los imaginarios culturales han influido en el enfoque de género de las profesiones y actividades productivas realizadas por mujeres y hombres, al respecto afirma Munévar (2009) que hay una tendencia a la feminización de profesiones como la salud, la educación, y una masculinización en profesiones como la agronomía, las ingenierías y afines, se registra mayor aumento de aspirantes femeninos en todas las carreras actualmente, a pesar de ello, la participación en grupos de funciones decisorias como consejos nacionales o consultorías, es mayoritariamente masculina.

Estudios de la relación entre la resolución de problemas de ciencia entre niños y niñas evidencian que la dificultad en un aula de clase es equivalente, y que al parecer no hay una relación de género determinante como la que puede encontrarse en matemáticas donde los niños regularmente tienen mejor desempeño o en castellano donde tienen las niñas mejor desempeño (Postigo, Pérez Echeverría M. y Sanz Á. 1999).

Por lo anterior se considera que los estudios revisados muestran la dificultad que se encuentra a la hora de explicar si el profesorado, desde sus mediaciones tienen 
Revista Tecné, Episteme y Didaxis: TED. Año 2014, Número Extraordinario. ISSN Impreso: 0121-3814, ISSN web: 2323-0126

Memorias, Sexto Congreso Internacional sobre Formación de Profesores de Ciencias. 08 al 10 de octubre de 2014, Bogotá

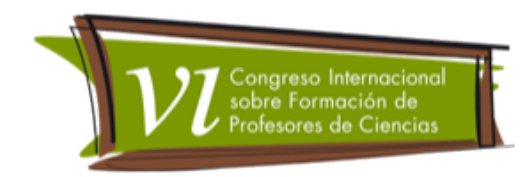

influencia alta o baja y qué puede determinar esta intervención. Por lo que se hace necesario revisar la relación docente, escuela y género.

\section{Profes@r, escuela y género}

El profesorado en la escuela juega un papel tan importante como la misma escuela, éste genera espacios de enseñanza / aprendizaje junto con l@s estudiantes desde un currículo formal, pero pocas veces se ha buscado estudiar el currículo oculto que se lleva al aula de clase por parte del profesorado a propósito de la temática que nos convoca, entendiéndose como currículo oculto todo aquello que los profesores dicen, el cómo lo dicen, gestos, comentarios, que permiten mediar lo que está escrito y validado de su currículo formal, en esta vía Flores (2005), plantea que el lenguaje es un instrumento de poder, a la vez Jiménez (2007) menciona que el lenguaje es un espacio de construcción de género y que la construcción del género en la sociedad no es neutral sino más bien está vinculada a las relaciones de poder que se institucionalizan en la sociedad actual.

Los docentes en general son agentes de cambio de la sociedad, la función social que cumplen va más allá de divulgar saberes especializados, ellos ejecutan los fines educativos que reflejan el ideario de ciudadano que se espera o el que ha construido la sociedad a la que pertenece. Muchas veces la desigualdad de género se presenta sin que el profesor o profesora se percaten de este, a pesar de que en el ambiente predomine la igualdad de condiciones, ya que están insertos en ese modelo de lo femenino y de lo masculino que se ha construido, un ejemplo de lo dicho son los libros guía que se llevan y estudian en el aula de clase, donde se visibilizan imágenes de científicos, y muy pocas veces a científicas mostrando un poder donde predominan unas personas sobre otras, validando y fortaleciendo el imaginario de una ciencia a-política, y a-histórica (Rossetti 1994).

Lo que es claro, es que el profesorado que direcciona de manera importante en las elecciones profesionales de las personas, cambiar o por lo menos esperar que el imaginario cultural de feminización o masculinización de las profesiones cambie, depende de lo que al respecto se construya en un aula, no es desconocido que el principal escenario de socialización de la cultura es la escuela con responsabilidad directa del profesorado. 
Revista Tecné, Episteme y Didaxis: TED. Año 2014, Número Extraordinario. ISSN Impreso: 0121-3814, ISSN web: 2323-0126

Memorias, Sexto Congreso Internacional sobre Formación de Profesores de Ciencias. 08 al 10 de octubre de 2014, Bogotá

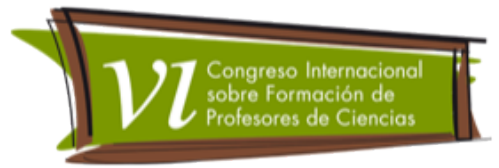

\section{Metodología}

Este es un estudio de enfoque cualitativo y carácter exploratorio el cual busca comprender cómo influye la perspectiva de género en las prácticas educativas, y qué tipos de relaciones subyacen entre la identidad profesional y el género.

Tipo estudio de caso, dado que la población seleccionada corresponde a profesor@s en formación inicial de la Licenciatura en Química.

Entre los instrumentos para la colecta de datos se cuenta con: encuestas y entrevistas, que permitan rastrear los intereses que motivan este trabajo al emplear genealogías de científicas como contexto problematizador con la población elegida.

La imagen que se presenta a continuación resume las fases del proyecto.

Imagen 1: planteamineto de la metodologia.

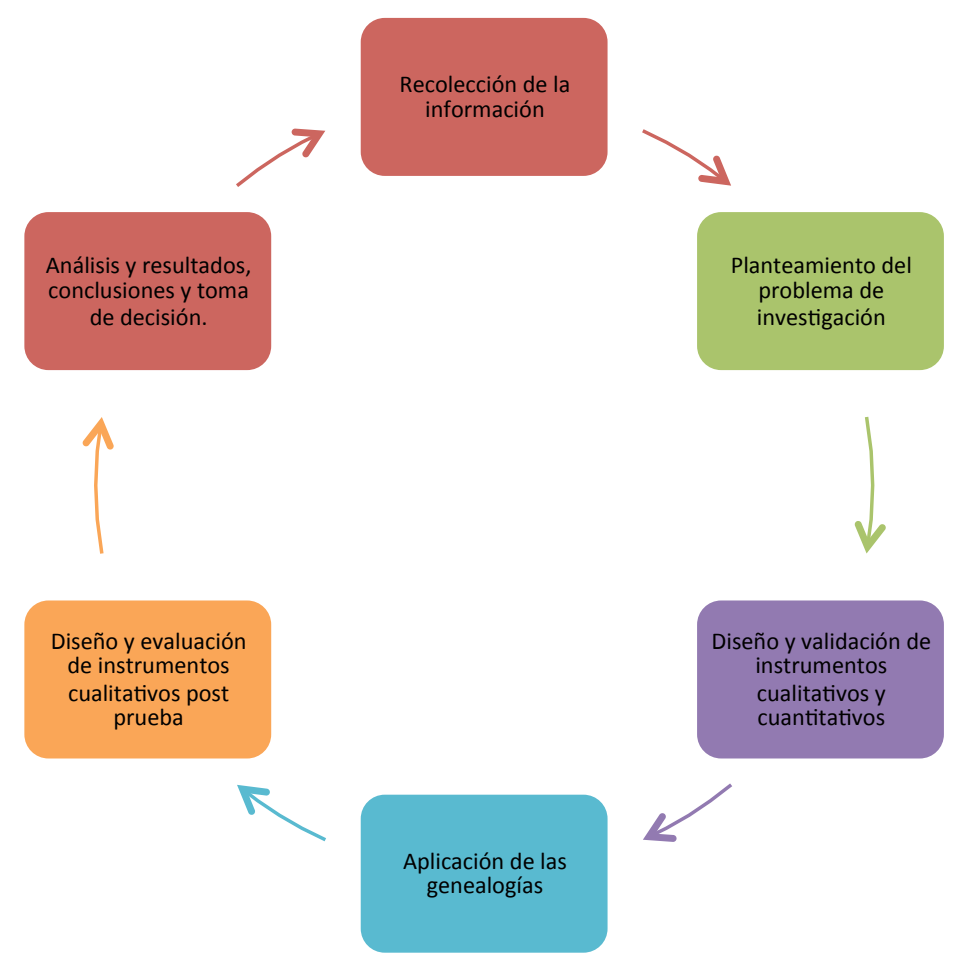


Revista Tecné, Episteme y Didaxis: TED. Año 2014, Número Extraordinario. ISSN Impreso: 0121-3814, ISSN web: 2323-0126

Memorias, Sexto Congreso Internacional sobre Formación de Profesores de Ciencias. 08 al 10 de octubre de 2014, Bogotá

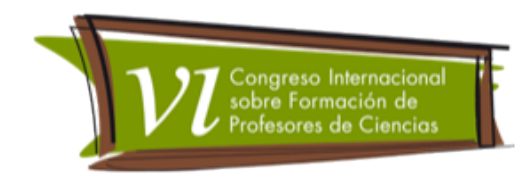

\section{Algunos Resultados}

Si bien se han adelantado las fases de diseño, no se ha ejecutado la totalidad de la implementación por lo tanto, los resultados aquí socializados corresponden con los análisis de la primera parte de ejecución.

\section{Sobre La Imagen De Género En Ciencias}

Para realizar indagaciones preliminares con la población objeto de estudio, sobre las perspectivas de género que tienen, o como ven el tema de género en la ciencia y principalmente en la enseñanza, se planteó un instrumento que indagó sobre aspectos como los que se citan a continuación:

Factor incidente para elegir la licenciatura en química ; el 70\% porcientos de los estudiantes respondieron que la toma de decisión sobre su perfil profesional fue influido por la imagen de su profesor/a de la secundaria o de sus últimos años de formación académica, aspecto que se contrastó con lo que menciona Dorr y Quevedo (2010): La influencia de los profesores es tan alta que permiten que los espacios académicos sean espacios de cambio y de transformación, si esto es para escoger perfiles ligados a la enseñanza cuanto más seria si se ligara a apropiación científica por parte de todos los seres humanos, entendiéndose la ciencia como una gran fábrica de seres humanos los cuales no son escogidos por su género, estereotipo, clase social.

Sobre la relación género ciencia, un total del $80 \%$ de los estudiantes considera que la ciencia no tiene género, sin embargo al identificar dentro de una lista de 7 personajes históricos de la química se evidencia que los personajes con mayor reconocimiento son Antoni Lauren Lavoisier y Mari Curie, se infiere este resultado en la medida que son los personajes que más se resaltan en libros de enseñanza de la química.

Al revisar los personajes que menos son recordados o visibilizados en la ciencia en general y a la química en particular se encontró con el menor puntaje a Dorithy Crowfoot Hodgkin y Rosalind Franklin, resultado que permite sostener la necesidad de reforzar la imagen científica femenina en los y las docentes en general, puesto que es evidente el reconocimiento del trabajo de hombres científicos, y poco el reconocimiento en mujeres científicas, entre otras cosas porque la visibilidad en la esfera pública es escaso. En palabras de Robayo (2013), el profesorado al no conocer una problemática permite que se continúe reforzando la naturalización la desigualdad de género en el aula de clase. 
Revista Tecné, Episteme y Didaxis: TED. Año 2014, Número Extraordinario. ISSN Impreso: 0121-3814, ISSN web: 2323-0126

Memorias, Sexto Congreso Internacional sobre Formación de Profesores de Ciencias. 08 al 10 de octubre de 2014, Bogotá

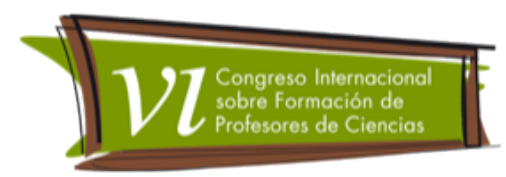

Grafica 3. Grado de visibilidad de algunos personajes en la ciencia en general y de la química en particular tomados de la muestra problema de esta investigación

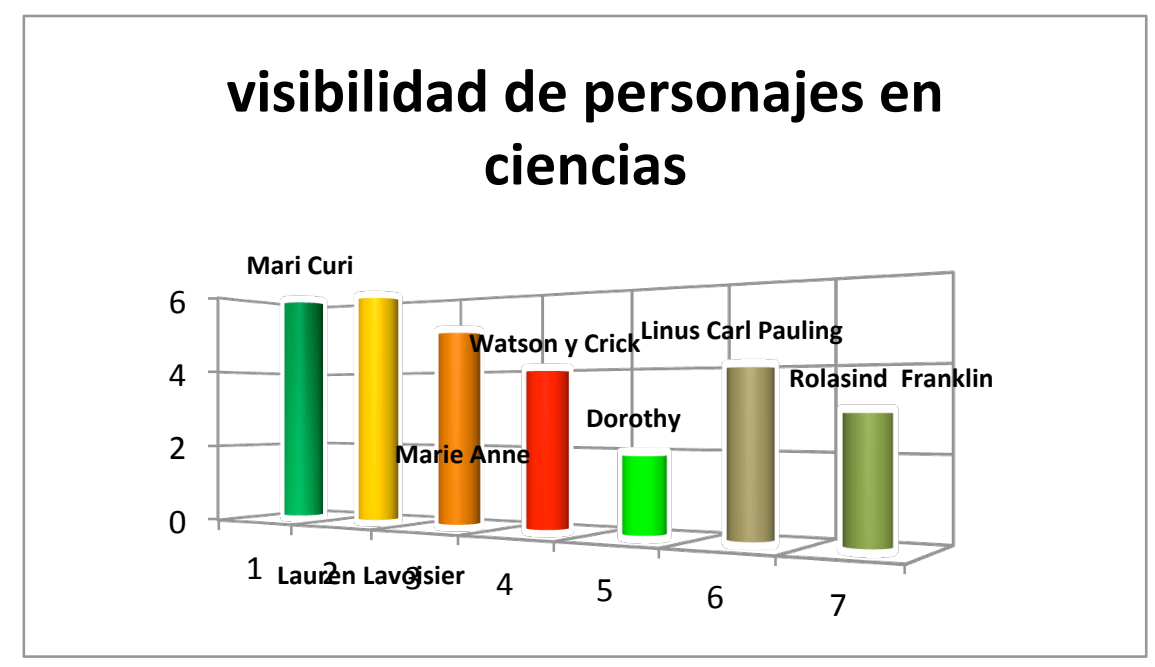

La grafica 2 permite afirmar que sólo distinguen a Lavoisier, y a Mari Curi, permitiendo inferir que existe un alto desconocimiento por otras personas que permitieron un avance en la ciencia y que fueron de vital importancia en un momento histórico de la ciencia, como ejemplo de esto Dorothy Hodgkin premio nobel de Química en 1964 por sus aportes en la estructura de la vitamina B12 y penicilina (Portugal, 1990).

\section{Las Genealogías Como Instrumento De Trabajo}

En la actualidad se reconoce las genealogías como estudios retrospectivos que corresponden con reconstrucciones históricas de la vida de personas desde el enfoque de historia social, por lo anterior, la genealogía que se planteó atiende a aspectos como:

\section{- Vida}

Este aspecto atiende a la necesidad de conocer cuáles fueron las condiciones sociales, económicas, políticas en las que se desarrolló la persona en cuestión, de igual manera se puede inferir cuál era su actuación dentro de su familia, relaciones con sus padres, poción económica y educación que recibió en sus años de infancia, primeras destrezas e intereses, ejemplo de esto es la preparación de la genealogía de Rosalind Franklin en la cual se encontró que era de descendencia judía, nació en Inglaterra y desde muy pequeña demostraba habilidades para las matemáticas y los idiomas, para ese entonces 
Revista Tecné, Episteme y Didaxis: TED. Año 2014, Número Extraordinario. ISSN Impreso: 0121-3814, ISSN web: 2323-0126

Memorias, Sexto Congreso Internacional sobre Formación de Profesores de Ciencias. 08 al 10 de octubre de 2014, Bogotá

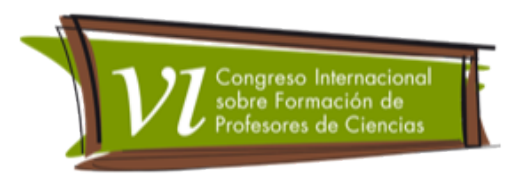

no se les permitía estudiar en la universidad carreras concernientes a las ciencias básicas (Romero, 2011)

\section{- Madre y Esposa}

El aspecto concerniente a su vida personal y en calidad de esposa y como madre permite considerar cuál era el roll social femenino en esta época, teniendo una familia y si influía o no en sus proyecciones como científica, investigadora, estudiante, cuál era la influencia social que ejercicio sobre la idea de ser madre y esposa y a la vez científica e investigadora, para el caso de Rosalind Franklin no se encontró rastros sobre su vida personal como madre y esposa, posiblemente por que las mujeres que trabajaban en el College King's si llegaban a contraer matrimonio debían renunciar a sus estudios (Romero, 2011)

\section{- Científica y Colaboradora}

Cuando se propone trabajar la historia desde los aportes hechos como científica y colaboradora se pretende dar el reconocimiento por su productividad, evidenciar las problemáticas que se presentaron a nivel social, económico y político que fueron direccionando la vida de cada protagonista de esta historia, cada segmento de este relato está considerado desde una visión de género visto no como las problemáticas que se le presentan a las mujeres sino como forma de hacer ver la igualdad entre todos los seres humanos, no se trata de reprimir un género sobre otro, o que el género masculino ha mantenido a sus pares en un mundo patriarcal, lo propicio con este tipo de trabajos es evidenciar que problemáticas se han presentado y promover un mundo diferente, capaz de buscar mayores estándares de igualdad entre todos los seres humanos.

\section{Reflexiones Finales}

A manera de conclusión es posible mencionar que las perspectivas de género que tienen los profesores son de difícil clasificación en la medida que no ha sido un elemento de trabajo teórico en su formación inicial y en cuanto al legado cultural es evidente que es de corte puramente androcentrista. Aspecto evidente cuando se habla de mujeres en ciencias,siendo el desconocimiento de los trabajos y vidas el primer elemento identificado.

A la hora de considerar aspectos históricos de la química desde el género se identifican elementos que permiten identificar el manejo de una ciencia ahistórica, como menciona Lakatos (1978, con afirmaciones en escenarios 
Revista Tecné, Episteme y Didaxis: TED. Año 2014, Número Extraordinario. ISSN Impreso: 0121-3814, ISSN web: 2323-0126

Memorias, Sexto Congreso Internacional sobre Formación de Profesores de Ciencias. 08 al 10 de octubre de 2014, Bogotá

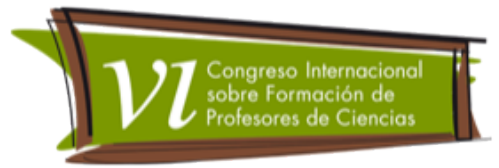

internalistas puesto que se ha reducido la identificación a los hechos que sostienen un cuerpo teórico y no a los sujetos que lo produjeron.

Por tal razón las genealogías al ser ejercicios de corte retrospectivo permiten conocer el origen de la historia desde las condiciones de vida, oficios, destrezas, religión, de los sujetos; es una opción de trabajo para profesores en formación inicial, ya que requiere de un trabajo colaborativo, en busca del reconocimiento y un continuo proceso de reconstrucción de memoria.

En palabras de Rebollo (2013), el profesorado al no conocer una problemática permite que se continúe reforzando la naturalización de la desigualdad de género en el aula de clase, a este fenómeno se le denomina "ceguera de género", los jóvenes en el aula de clase al escuchar nuevas opiniones y pensamientos sobre la igualdad en este caso "género" permiten que estos puedan pensarse en un mundo diferente, equitativo y con un alto grado en valores humanos, "lo que no se habla no existe y lo que no existe no se practica" (Rebollo 2013).

Para finalizar Eynde (1994) afirma que el saber no es un ejercicio propio de un género, sino de la humanidad, reconociendo las distinciones en cuanto a la relación que pueden establecer tanto hombres como mujeres a propósito de la interpretación del mundo, es por esto que La escuela es un espacio de formación de las nuevas generaciones y materializadora de sueños de I@s niñ@s, el cual debe procurar por formar en valores de igualdad, solidaridad, y equidad en tod@s @@ que conforman la comunidad educativa y es de esta manera que los profesores deben comprender, asimilar y actuar, fomentando esos valores en la sociedad ya que Dentro de la escuela se refuerza con más intensidad las prácticas y el discurso de lo femenino y lo masculino (Flores 2005).

\section{Referencias b ibliográficas}

Daza y Pérez (2008). contando mujeres. Una reflexión sobre los indicadores de género y ciencia en Colombia, revista antropol. social. №. 10, pág. 29 - 51.

Díaz y Susa (2012). Mujeres científicas químicas: Una mirada desde los doctorados en Colombia, (trabajo de grado inédito de pregrado), Universidad Pedagógica Nacional, departamento de Química.

Eynde, Angeles. (1994). Género y ciencia, ¿̇términos contradictorios?, Un análisis sobre la contribución de las mujeres al desarrollo científico, revista 
Revista Tecné, Episteme y Didaxis: TED. Año 2014, Número Extraordinario. ISSN Impreso: 0121-3814, ISSN web: 2323-0126

Memorias, Sexto Congreso Internacional sobre Formación de Profesores de Ciencias. 08 al 10 de octubre de 2014, Bogotá

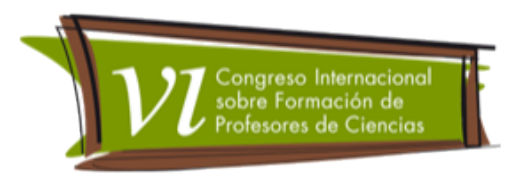

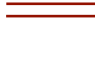
iberoamericana de educación, 6 Recuperado de http://www.oei.es/oeivirt/rie06a03.htm

Flores (2005). violencia de género en la escuela: sus efectos en la identidad, en la autoestima y en el proyecto de vida, Revista ARANGO 2, pág. 114-119.

Jiménez (2007), discurso de género y práctica docente, universidad de Málaga, revista de investigación educativa, Vol. 25(1), pág. 59-76.

Lakatos I. (1978). La metodología de los programas de investigación científica, Madrid-España: Alianza editorial, S.A.

Ley general de educación, decreto número 5, de los fines de la educación (1994).

Munévar, D. (2009). Rehaciendo el mundo de los saberes, Revista científica UCES, 20 (2), pág. 158-216, Recuperado de: http://dspace.uces.edu.ar:8180/xmlui/bitstream/handle/123456789/739/Reh aciendo_el_mundo_de_los_saberes.pdf? sequence $=1$

Observatorio Colombiano De Ciencia Y Tecnologia, OC y T (2012). indicadores estadísticos, Jorge Lucio... [et al.]. - Bogotá, recuperado de http://ocyt.org.co/html/archivosProyectos/OCyT\%20Indicadores\%202012.pdf

Portugal A. (1990). Las científicas olvidadas, mujer y ciencia investigación y circulo, pág. 145-148.

Rebollo A (2013). la innovación educativa con perspectiva de género. retos y desafíos para profesorado, revista de currículum y formación del profesorado, 17 (3), pág. 3-8.

Rossetti, (1994). Educación: la igualdad aparente entre hombre y mujeres, centro de investigación y desarrollo de la educación, pág. 2-104, Recuperado de http://biblioteca.vahurtado.cl/UJAH/856/txtcompleto/txt92619.pdf

Romero, (2011). ciencia y género. reflexiones sobre la invisibilización de la contribución de las mujeres al desarrollo de las ciencias. algunas propuestas didácticas, plan canario de actividades complementarias, gobierno de canarias, pág. 11-17, recuperado de http://web.ua.es/es/unidadigualdad/documentos/secundando-igualdad/pd-rosalind-and-marie.pdf 